\title{
"Candy cane" syndrome: a report of a mini-invasive endoscopic treatment using OverStitch, a novel endoluminal suturing system
}

A 25-year-old woman with a history of Barrett's esophagus with dysplasia underwent Ivor Lewis esophagectomy at the age of 18 years.

After 24 months, she developed dysphagia, postprandial vomiting, and epigastric pain, with progressive weight loss. Upper gastrointestinal (GI) series showed delayed gastric emptying with pre-pyloric stagnation.

After multiple, fruitless, endoscopic hydro-pneumatic dilations of the pylorus, the patient underwent Roux-en-Y gastrojejunostomy, with clinical benefit and weight regain.

One year later, symptoms recurred, with nausea and recurrent postprandial pain that resolved after vomiting. Upper GI series revealed direct filling of the blind afferent cul-de-sac with no spilling over into the efferent limb ( $>$ Fig. 1).

In order to avoid further hazardous surgery, and considering the young age of the patient, we decided to proceed with a minimally invasive approach. We attempted to obliterate the afferent limb, preventing the food from collecting in its lumen, and allowing the intestinal transit entirely into the efferent limb.

We used argon plasma coagulation to scar the entire cul-de-sac mucosal layer in order to promote cicatrization. We then proceeded to approximate the opposite enteric walls of the afferent limb, from the bottom to the top, by placing multiple purse-string sutures using the OverStitch Endoscopic Suturing System (Apollo Endosurgery, Inc., Austin, Texas, USA); total closure of the cul-desac was achieved ( $>$ Fig. 2, \ Video 1 ).

After treatment, the patient had complete resolution of symptoms. At the 1-month follow-up, upper Gl series showed direct transit of contrast dye into the efferent limb without any filling of the obliterated afferent lumen (॰ Fig.3).

"Candy cane" syndrome is a poorly described surgical complication [1-3]. In
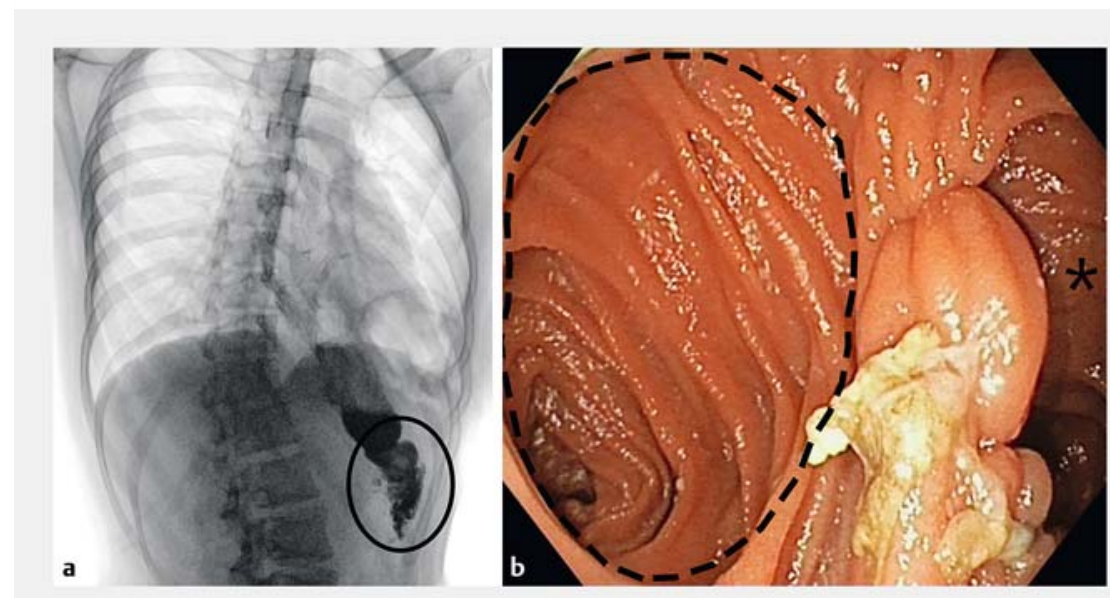

- Fig. 1 Preoperative work-up. a Upper gastrointestinal series showing contrast dye pooling in the dilated afferent blind limb (circle). b Endoscopic view of the afferent (dashed circle) and efferent (asterisk) limb.

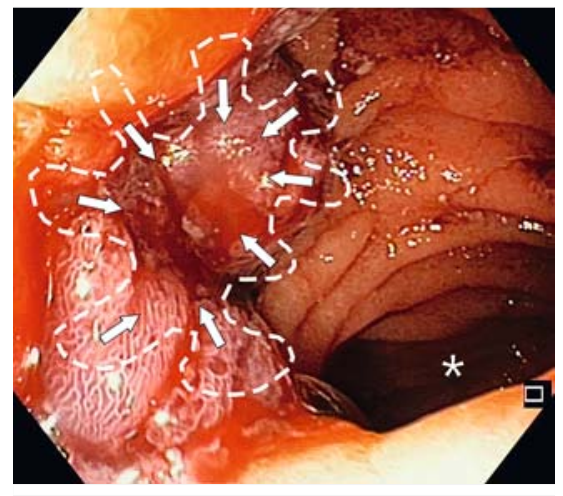

- Fig. 2 Complete obliteration of the blind afferent limb using multiple pursestring sutures (white dashed line), leaving total patency of the efferent limb (aster-

the largest published case series (19 patients), Aryaie at al. reported a success rate of $94 \%$ by laparoscopic resection of the redundant afferent limb [4]. In patients with "candy cane" syndrome, a minimally invasive endoscopic approach seems to be a valid alternative, especially in patients who are unfit for surgery and have critical medical conditions or a history of multiple surgical revisions.

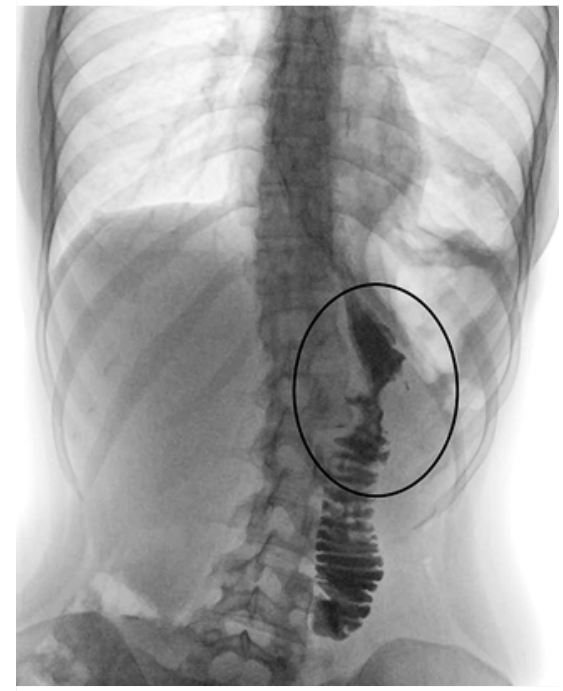

- Fig. 3 Upper gastrointestinal evaluation 1 month later showed direct transit of contrast dye into the efferent limb.

Endoscopy_UCTN_Code_TTT_1AQ_2A

Competing interests

None 


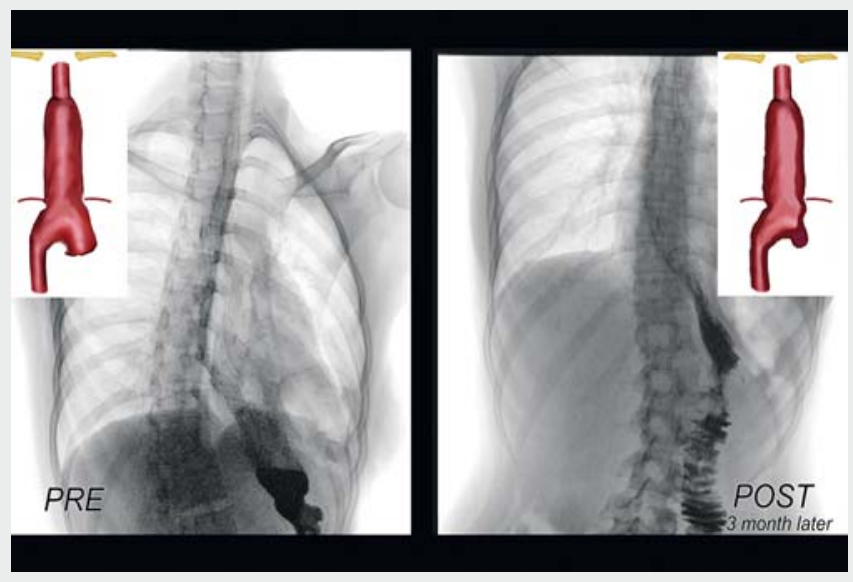

$\checkmark$ Video 1 A novel endoluminal suturing system applied for the treatment of the "Candy cane" syndrome, allows a mini-invasive endoscopic solution with complete resolution of symptoms in a young patient with a history of multiple surgical procedures.

The authors

Antonino Granata ${ }^{1}$, Noemi Cicchese ${ }^{1}$, Michele Amata ${ }^{1}$, Lavinia De Monte ${ }^{2}$, Alessandro Bertani $^{2}$, Dario Ligresti ${ }^{1}$, Mario Traina ${ }^{1}$

1 IRCCS - ISMETT, Endoscopy Service, Department of Diagnostic and Therapeutic Services, Palermo, Italy

2 IRCCS - ISMETT, Thoracic surgery, Department for the Treatment and Study of Cardiothoracic Diseases and Cardiothoracic Transplantation, Palermo, Italy

\section{Corresponding author}

\section{Antonino Granata, MD}

Endoscopy Service, IRCCS - ISMETT, Via

Tricomi, 5, 90127 Palermo, Italy

Fax: +39-091-2192400

agranata@ismett.edu

\section{References}

[1] Dallal RM, Cottam D. "Candy cane" Roux syndrome - a possible complication after gastric bypass surgery. Surg Obes Relat Dis 2007; 3: $408-410$
[2] Robert M, Pelascini E, Poncet G et al. Blind biliary limb dilatation (Candy cane syndrome) of jejuno-jejunal anastomosis after Roux en $\mathrm{Y}$ gastric bypass (with video). J Visc Surg 2018; 155: 239-241

[3] Romero-Mejía C, Camacho-Aguilera JF, Paipilla-Monroy O. ["Candy cane” Roux syndrome in laparoscopic gastric by-pass]. Cir Cir 2010; 78: 347-351

[4] Aryaie AH, Fayezizadeh M, Wen Y et al. "Candy cane syndrome": an underappreciated cause of abdominal pain and nausea after Roux-en-Y gastric bypass surgery. Surg Obes Relat Dis 2017; 13: $1501-1505$

\section{Bibliography}

DOI https://doi.org/10.1055/a-0756-8304

Published online: 7.11.2018

Endoscopy 2019; 51: E16-E17

(c) Georg Thieme Verlag KG

Stuttgart · New York

ISSN 0013-726X

\section{ENDOSCOPY E-VIDEOS}

https://eref.thieme.de/e-videos

Endoscopy E-Videos is a free access online section, reporting 回: on interesting cases and new techniques in gastroenterological endoscopy. All papers include a high quality video and all contributions are freely accessible online.

This section has its own submission website at

https://mc.manuscriptcentral.com/e-videos 